\title{
EFEITOS DA COVID-19 NOS COMPORTAMENTOS DE DESCARTE DO CONSUMIDOR E CENÁRIOS DE NEGÓCIOS FUTUROS
}

\section{EFFECTS OF COVID-19 ON CONSUMER DISPOSAL BEHAVIOR AND FUTURE BUSINESS SCENARIOS}

\section{MANOELA LAWALL RADTKE \\ Mestranda em Administração (PPGAd/PUCRS) \\ Pontifícia Universidade Católica do Rio Grande do Sul - PUCRS}

Orcid: https://orcid.org/0000-0002-8183-9865 / E-mail: radtkemanoela@gmail.com

Endereço: Avenida Ipiranga 6681 - Prédio 50 - Partenon, Porto Alegre (RS), 90619-900

\section{ANA LUIZA BROCK \\ Mestranda em Administração (PPGA/UFRGS) \\ Universidade Federal do Rio Grande do Sul - UFRGS}

Orcid: https://orcid.org/0000-0001-7388-3164?lang=en / E-mail: analuizabrock@gmail.com

\section{CRISTINA M. OSTERMANN}

Doutoranda em Administração (PPGA/UFRGS)

Universidade Federal do Rio Grande do Sul - UFRGS

Orcid: https://orcid.org/0000-0001-8399-3519 / E-mail: cris.ostermann@gmail.com

STEFÂNIA ORDOVÁS DE ALMEIDA

Doutora em Administração

Pontifícia Universidade Católica do Rio Grande do Sul - PUCRS

Orcid: https://orcid.org/0000-0002-4899-031X / E-mail: stefania.almeida@pucrs.br

Submissão: 15/08/2020. Revisão: 05/11/2020. Aceite: 26/11/2020. Publicação: 29/12/2020.

DOI: http://dx.doi.org/10.22277/rgo.v14i1.5750

\section{RESUMO}

Este estudo teve como objetivo compreender como a crise gerada pela pandemia da COVID19 impactou nos comportamentos de descarte do consumidor, discutindo os possíveis efeitos desses impactos para os negócios pós-COVID-19, com especial foco nas questões ligadas à sustentabilidade. Para tanto, foi realizada uma revisão descritiva de literatura sobre comportamentos de descarte em um primeiro momento. Após, foi realizada uma busca de artigos e dados sobre comportamento do consumidor e a crise da pandemia da COVID-19. Adicionalmente, identificou-se relatórios baseados em pesquisas de empresas e institutos privados que têm monitorado mudanças e tendências no comportamento de consumo. Os resultados apontam relações entre os comportamentos de descarte identificados na literatura e os possíveis impactos da COVID-19 nestes comportamentos. Ainda, foi possível verificar que o comportamento de descarte impacta em oportunidades de negócio e modelos de negócios sustentáveis.

Palavras-chave: Descarte. Comportamento do consumidor. COVID-19. Sustentabilidade. Negócios. 
Efeitos da COVID-19 nos comportamentos de descarte do consumidor e cenários de negócios futuros

\begin{abstract}
This study aims to understand how the crisis generated by the COVID-19 pandemic impacted consumer disposal behaviors, discussing the possible effects of these impacts on post-COVID19 businesses, with a special focus on sustainability. For this purpose, a descriptive literature review on disposal behavior was performed at first. Afterwards, a search was made for articles and data on consumer behavior and the COVID-19 virus pandemic crisis. Additionally, reports based on surveys of companies and private institutes that have monitored changes and trends in consumer behavior have been identified. The results show relationships between the disposal behaviors identified in the literature and the possible impacts of COVID-19 on these behaviors. It was also possible to verify that the disposal behavior impacts on business opportunities and sustainable business models.
\end{abstract}

Keywords: Disposal. Consumer behavior. COVID-19. Sustainability. Business.

\title{
1 INTRODUÇÃO
}

Os consumidores são importantes influenciadores de práticas e modelos econômicos e de negócios sustentáveis. Sua influência se dá em todas as etapas de consumo, desde a escolha de compra de bens e serviços, o cuidado e manutenção dos bens, até a escolha da destinação dos itens e resíduos (MCNEILL et al., 2020). Assim como a aquisição e o consumo, o descarte também é considerado uma etapa do comportamento do consumidor (JACOBY et al., 1977; TING et al., 2019) e é visto como uma prática de consumo sustentável (WHITE et al., 2019). Ainda, os comportamentos de descarte são essenciais em termos de desenvolvimento sustentável, devido às mudanças climáticas verificadas nos últimos anos (WHITE et al., 2019). A extensão do ciclo de vida dos materiais tem sido apontada como alternativa para reduzir os impactos econômicos, ambientais e sociais dos sistemas de produção e das práticas de consumo do atual sistema econômico (GEISSDOERFER et al., 2017).

A crise mundial causada pela pandemia da COVID-19 ressaltou a necessidade de práticas empresariais e de consumo que considerem os impactos em termos de sustentabilidade (MCKINSEY; COMPANY, 2020). Pesquisadores apontam que a redução da biodiversidade pode favorecer o surgimento de novas pandemias (TOLLEFSON, 2020). Ademais, a crise teve consequências também nas esferas econômica e social. As medidas tomadas mundialmente para contenção da pandemia resultaram em impactos negativos sobre a economia e a renda da população mundial, com forte efeito no Brasil (KOMATSU; MENEZES-FILHO, 2020). Os comportamentos sociais também foram impactados. Por exemplo, verificou-se aumento do número de consumidores que preferem direcionar seus recursos para negócios de sua comunidade, em colaboração com o desenvolvimento regional (HIBOU; INDICO, 2020). Também, houve aumento na distribuição de renda espontânea para os mais afetados pela crise, por meio de doações e redes colaborativas (GOOGLE; IAT, 2020; MUTATO, 2020).

Do ponto de vista empresarial, a mudança nas práticas e padrões de consumo cria um ambiente propício para o surgimento de novos modelos de negócio. Para os modelos de negócio existentes, surge a necessidade de readaptação da proposta de criação e entrega de valor, alinhados à nova realidade pós-COVID-19. Fatores como uso intensivo de tecnologia, preocupação com a sustentabilidade, restrições financeiras em âmbito público e privado, mudança nas necessidades dos clientes (tantos em negócios B2B quanto B2C) geram impactos 
Manoela Lawall Radtke, Ana Luiza Brock, Cristina M. Ostermann e Stefânia Ordovás de Almeida Oliveira

importantes do ponto de vista gerencial e de negócios, tornando um campo importante para pesquisas.

Nesse contexto, o comportamento de descarte torna-se ainda mais relevante pois a prática tem efeitos tanto na dimensão econômica, como ambiental e social. As práticas de descarte podem reduzir o volume de material descartado e estender a vida útil dos produtos, reduzindo o uso de novas matérias-primas. Práticas que envolvem benefício monetário ao consumidor tendem a aumentar, gerando novas oportunidades de negócios e emprego e reorganização da cadeia de valor.

No senso comum, a ideia de descarte abrange a perspectiva de desfazer-se de um produto. Academicamente, o conceito é tratado de forma mais ampla e define diversos comportamentos como atrelados ao descarte, contemplando também estudos sobre o significado das posses, o objetivo dos comportamentos de descarte e os canais de descarte (BALLANTINE; CREERY, 2010). Grande parte da pesquisa sobre comportamento de consumo concentra-se na etapa de aquisição de produtos e nas considerações e processos que determinam como os consumidores tomam decisões de compra, tratando o comportamento de descarte de forma periférica ou até mesmo ignorando-o (TING et al., 2019). Apesar do crescente número de estudos relacionados ao comportamento de descarte (CRUZ-CÁRDENAS; ARÉVALO-CHÁVEZ, 2018), há carência de estudos visando à sistematização dos comportamentos do consumidor quanto ao descarte de produtos descritos na literatura.

Dessa forma, percebe-se uma lacuna acadêmica a ser preenchida e relacionada aos estudos do comportamento de consumo de descarte, assim como a possibilidade de relevante contribuição gerencial e social na análise desse tema aplicada ao momento atual. Assim, o presente estudo buscou responder à seguinte questão de pesquisa: como a crise gerada pela pandemia da COVID-19 impactou nos comportamentos de descarte do consumidor? Adicionalmente, procurou-se discutir os possíveis efeitos desses impactos para os negócios pós-COVID-19, com especial foco nas questões ligadas à sustentabilidade. Para tanto, foi realizada uma investigação exploratória, baseada em revisão descritiva de literatura sobre os comportamentos de descarte do consumidor e sobre as mudanças no comportamento de consumo ocasionadas pela pandemia da COVID-19. Os dados obtidos permitiram (i) a sistematização dos comportamentos de descarte descritos pela literatura; (ii) a identificação de mudanças e tendências no comportamento de consumo durante e pós-crise; (iii) a proposição de efeitos da crise da COVID-19 no comportamento de descarte e (iv) exploração do impacto desse cenário nos negócios pós-COVID-19.

\section{FUNDAMENTAÇÃO TEÓRICA}

O referencial teórico deste estudo foi dividido em duas seções. Na primeira, apresentase uma discussão acerca do comportamento de descarte e sustentabilidade. Em seguida, realiza-se uma discussão sobre a COVID-19 e os efeitos no comportamento de consumo.

\subsection{COMPORTAMENTO DE DESCARTE E SUSTENTABILIDADE}

O processo de consumo é composto por uma sequência de comportamentos antes, durante e após a compra (JACOBY et al., 1977; BIANCHI; BIRTWISTLE, 2010). A etapa póscompra é composta por comportamentos do consumidor relacionados ao uso, cuidado e manutenção e descarte do produto após o uso (LAITALA, 2014). Portanto, o descarte pode ser entendido como a parte final do ciclo de consumo (STÅL; JANSSON, 2017). 
Do ponto de vista do ciclo de vida dos materiais, o descarte encerra um ciclo de uso e pode significar tanto o final da vida útil como a reinserção dos materiais em um novo ciclo de utilização. Novos ciclos de utilização estendem o ciclo de vida e reduzem a retirada de matérias-primas da natureza, resultando na preservação dos sistemas ecológicos e redução do impacto ambiental (KORHONEN et al., 2018). A produção de novos produtos gera externalidades tais como emissão de gases poluentes, emissão de resíduo sólidos, uso de água, de energia e da terra. Somam-se aos impactos de produção os gerados por logística, transporte e distribuição, que resultam em uso de combustíveis fósseis e emissões de gases poluentes, entre outros (KOZLOWSKI et al., 2012). Dessa forma, os comportamentos relacionados às decisões de descarte têm implicações sustentáveis e são considerados como uma dimensão do consumo sustentável (WHITE et al., 2019; BIANCHI; BIRTWISTLE, 2010).

$\mathrm{Na}$ área de sustentabilidade, a Economia Circular é considerada a mais recente estratégia de sistema econômico para o desenvolvimento sustentável e baseia-se em ciclos fechados e o redesenho de produtos e processos, buscando práticas restaurativas (GEISSDOERFER et al., 2017). Na Economia Circular, as rotas de recuperação e regeneração concentram-se principalmente em recirculação de materiais pós-consumo por meio de 3 princípios: redução, reuso e reciclagem (SINGH; ORDOÑEZ, 2016), sendo todos impactados pelos comportamentos de descarte. Por exemplo, Armstrong et al. (2015) citam como oportunidades para redução do impacto ambiental i) a produção de produtos com maior qualidade e, consequentemente, maior vida útil, ii) a redução do descarte em aterros e iii) o aumento da demanda do mercado de itens usados.

Ainda, o consumidor pode ser destacado como importante ator nas estratégias de sustentabilidade na medida em que participa ativamente em diversas etapas da cadeia de consumo: na aquisição de bens e serviços, sendo influenciador de práticas e modelos de produção; na manutenção dos bens, visando sua durabilidade e reaproveitamento e na destinação correta dos resíduos e bens após seu uso (BORRELLO et al., 2017). A decisão do consumidor sobre a destinação dos produtos após o ciclo de utilização está articulada com outros comportamentos de consumo e impacta no processo de compra de outros produtos (CRUZ-CÁRDENAS; ARÉVALO-CHÁVEZ, 2018). Ainda, a decisão sobre o descarte é uma escolha pessoal do consumidor, já que a destinação dos produtos para os diferentes canais de descarte é resultado da sua avaliação individual (WEBER et al., 2017).

Em termos de comportamentos de descarte descritos pela literatura, identifica-se uma falta de clareza sobre os limiares entre um tipo de comportamento e outro, existindo sobreposições e até mesmo o tratamento de comportamentos diferentes como sinônimos. Somado a isso, o comportamento de descarte é entendido como complexo, visto que muitas vezes é difícil a identificação do último destino dos bens em função do prolongamento do ciclo de vida dos produtos (BOYD; MCCONOCHA, 1996). Contudo, a repetição de certas definições demonstra maior aceitação de aspectos específicos de cada comportamento, o que permite a sistematização dos comportamentos. O Quadro 1 apresenta a definição dos comportamentos e como ocorrem, a partir da revisão de literatura realizada. 
Manoela Lawall Radtke, Ana Luiza Brock, Cristina M. Ostermann e Stefânia Ordovás de Almeida Oliveira

Quadro 1 - Definições e características dos comportamentos de descarte

\begin{tabular}{|c|c|c|}
\hline Tipo & Definição & Como ocorre \\
\hline Dar & $\begin{array}{l}\text { Comportamento que não resulta } \\
\text { em obtenção de ganho financeiro } \\
\text { por parte de quem está } \\
\text { descartando o produto (BIANCHI; } \\
\text { BIRTWISTLE, 2010). O O } \\
\text { comportamento de "dar" pode } \\
\text { ser confundido com o de "doar" } \\
\text { ou "(re)presentear". }\end{array}$ & $\begin{array}{l}\text { Tem como objetivo principal a destinação para } \\
\text { indivíduos com laços próximos, principalmente } \\
\text { familiares e amigos (BIANCHI; BIRTWISTLE, 2010). Em } \\
\text { relação à sustentabilidade, Bianchi e Birtwistle (2010) } \\
\text { identificaram que consumidores ligados à moda e que } \\
\text { possuem uma preocupação com questões relacionadas à } \\
\text { sustentabilidade têm maior probabilidade de dar suas } \\
\text { roupas para familiares e amigos. }\end{array}$ \\
\hline Doar & $\begin{array}{l}\text { É um dos comportamentos de } \\
\text { descarte mais citados na } \\
\text { literatura (NORUM, 2017). Tem } \\
\text { como principal característica o } \\
\text { repasse para um desconhecido } \\
\text { (HARRELL; MCCONOCHA, 1992), } \\
\text { sendo as instituições de caridade, } \\
\text { laicas ou religiosas, os destinos } \\
\text { mais citados. Os doadores não } \\
\text { possuem fins lucrativos com a } \\
\text { doação, mas as instituições de } \\
\text { caridade podem tanto repassar os } \\
\text { donativos para o beneficiário } \\
\text { final, quanto vendê-los para } \\
\text { retorno financeiro, direcionando } \\
\text { o dinheiro arrecadado para suprir } \\
\text { outras demandas (BIRTWISTLE; } \\
\text { MOORE, 2007; HIBBERT et al., } \\
\text { 2005). Apesar do lucro não ser um } \\
\text { objetivo da doação, doadores } \\
\text { podem receber benefícios } \\
\text { financeiros indiretos, como } \\
\text { abatimentos em taxas fiscais } \\
\text { (BOYD; MCCONOCHA, 1996), e as } \\
\text { razões para a doação podem não } \\
\text { ser, necessariamente, atos } \\
\text { puramente altruístas (HARRELL; } \\
\text { MCCONOCHA, 1992). }\end{array}$ & $\begin{array}{l}\text { A doação ocorre por diversos meios, sendo alguns: a } \\
\text { entrega de sacolas vazias em bairros para posterior } \\
\text { recolhimento com donativos, em um modelo de logística } \\
\text { reversa comunitária (GREGSON; BEALE, 2004; HIBBERT } \\
\text { et al., 2005); a partir da coleta por meio de caminhões da } \\
\text { caridade (BIRTWISTLE; MOORE, 2007); e entregas em } \\
\text { bancos de roupas, evitando, assim, problemas de } \\
\text { logística reversa (HIBBERT et al., 2005). Arangdad et al. } \\
\text { (2019) identificaram que a há maior probabilidade de } \\
\text { realizar a doação de roupas se os locais de entrega } \\
\text { estiverem a uma curta distância das suas residências, } \\
\text { sugerindo que a conveniência pode ser um fator } \\
\text { importante para esse comportamento. }\end{array}$ \\
\hline Devolver & $\begin{array}{l}\text { Compreende o momento em que } \\
\text { o produto retorna à sua origem, } \\
\text { seja pela verificação de benefício } \\
\text { em políticas ou programas de } \\
\text { devolução, ou ao receber um } \\
\text { presente que, por algum motivo, } \\
\text { precisa ser devolvido. A literatura } \\
\text { indica que o comportamento de } \\
\text { devolução ocorre por meio de } \\
\text { dois aspectos principais: } \\
\text { devoluções observando as } \\
\text { políticas de troca e programas de } \\
\text { devolução que visam ao processo } \\
\text { de logística reversa. }\end{array}$ & $\begin{array}{l}\text { O comportamento de devolução pode ser causado por } \\
\text { presentes indesejados ou pela compra de produtos que } \\
\text { não atendem às expectativas ou necessidades do } \\
\text { consumidor (SHERRY et al., 1992; BOYD; MCCONOCHA, } \\
\text { 1996). Além disso, pode ser realizado por meio de } \\
\text { programas de reciclagem, em que o consumidor devolve } \\
\text { o produto para o varejo realizar o descarte correto (Gaur } \\
\text { et al., 2017). O comportamento de devolver impacta no } \\
\text { processo de aquisição - as facilidades na devolução para } \\
\text { o varejo a partir de políticas de crédito, reembolso ou } \\
\text { troca em loja influenciam proporcionam ao consumidor } \\
\text { maior segurança na aquisição e podem resultar na } \\
\text { compra de produtos excedentes - e em outros } \\
\text { comportamentos de descarte - por exemplo, podem } \\
\text { reduzir as doações para instituições de caridade (BOYD; } \\
\text { MCCONOCHA, 1996). }\end{array}$ \\
\hline Emprestar & $\begin{array}{l}\text { O comportamento de } \\
\text { "emprestar" ocorre quando se } \\
\text { permite o uso de um produto por }\end{array}$ & $\begin{array}{l}\text { Verifica-se prevalência do comportamento em artigos } \\
\text { sobre o empréstimo de produtos infantis (GREGSON et } \\
\text { al., 2007). No estudo de Gregson et al. (2007), as práticas }\end{array}$ \\
\hline
\end{tabular}


Efeitos da COVID-19 nos comportamentos de descarte do consumidor e cenários de negócios futuros

\begin{tabular}{|c|c|c|}
\hline & $\begin{array}{l}\text { outra pessoa por um tempo } \\
\text { determinado, com devolução ao } \\
\text { proprietário ao final desse } \\
\text { período. }\end{array}$ & $\begin{array}{l}\text { de desinvestimento de artigos infantis (berço, } \\
\text { brinquedos, roupas e outros) são encaradas também } \\
\text { como uma forma de transmitir valores para os filhos, } \\
\text { com intuito de mostrá-los que, caso o objeto não tenha } \\
\text { mais valor funcional, ele deve ser passado adiante. Sego } \\
\text { (2010) buscou explorar os significados atribuídos aos } \\
\text { itens das crianças que são descartados por diferentes } \\
\text { canais. Os produtos escolhidos para serem emprestados } \\
\text { a outras famílias foram aqueles elencados com grande } \\
\text { significado pessoal e alto valor para outras famílias, } \\
\text { sendo o retorno do produto uma condição. }\end{array}$ \\
\hline Guardar & $\begin{array}{l}\text { É usado para manter ou } \\
\text { armazenar objetos que ficam fora } \\
\text { de uso e está atrelado a } \\
\text { motivações diferentes. Pode ser } \\
\text { associado ao apego por uma } \\
\text { pessoa que ofereceu um presente } \\
\text { (JACOBY et al., 1977; SHERRY et } \\
\text { al., 1992), ou associado a uma } \\
\text { identidade que se deseja manter } \\
\text { (PRICE et al., 2000). }\end{array}$ & $\begin{array}{l}\text { Pode anteceder outros comportamentos de descarte, } \\
\text { pois auxilia no enfraquecimento da ligação entre a } \\
\text { identidade do sujeito em relação à detenção do objeto } \\
\text { (LASTOVICKA; FERNANDEZ, 2005). A prática apresenta } \\
\text { um paradoxo: há uma saída de circulação da posse, } \\
\text { porém seu dono a mantém consigo. }\end{array}$ \\
\hline Jogar fora & $\begin{array}{l}\text { Pode ser definido como um } \\
\text { comportamento de descarte } \\
\text { permanente, em que o produto } \\
\text { não será reutilizado ou reciclado } \\
\text { de nenhuma maneira. (EVERS et } \\
\text { al., 2018; HANSON; 1980; SHIM, } \\
\text { 1995). }\end{array}$ & $\begin{array}{l}\text { Muitos estudos que abordam este comportamento } \\
\text { estão ligados a questões de sustentabilidade (NORUM, } \\
\text { 2017; WINTERICH et al., 2019). Ainda, Norum (2017) } \\
\text { desenvolveu um estudo com o intuito de compreender a } \\
\text { tomada de decisão de descarte no lixo e concluiu que as } \\
\text { peças de vestuário que o consumidor entende não } \\
\text { estarem em boas condições eram, majoritariamente, } \\
\text { jogadas no lixo. }\end{array}$ \\
\hline (Re)presentear & $\begin{array}{l}\text { O processo de "(re)presentear" é } \\
\text { usado quando algum amigo, } \\
\text { vizinho ou familiar recebe um } \\
\text { presente que é repassado com } \\
\text { status de novo, sendo que o } \\
\text { destinatário desconhece que é um } \\
\text { "represente" (ERTIMUR et al., } \\
\text { 2015), e pode ser consequência } \\
\text { do recebimento de um presente } \\
\text { indesejado (SHERRY et al. 1992). }\end{array}$ & $\begin{array}{l}\text { Percebe-se uma ênfase no que diz respeito ao } \\
\text { comportamento de presentear ou (re)presentear que } \\
\text { tratam de produtos de vestuário (CRUZ-CÁRDENAS; DEL } \\
\text { VAL NÚÑEZ, 2016; CRUZ-CÁRDENAS et al., 2017). A } \\
\text { literatura entende que o descarte como forma de } \\
\text { presentear é mais demorado do que a doação, por } \\
\text { exemplo, pois o processo de presentear necessita de } \\
\text { uma identificação de potenciais destinatários do objeto } \\
\text { (CRUZ-CÁRDENAS; DEL VAL NÚÑEZ, 2016). }\end{array}$ \\
\hline Reutilizar & $\begin{array}{l}\text { A reutilização ocorre quando um } \\
\text { produto é modificado para ser } \\
\text { usado de outra forma ou com } \\
\text { outra finalidade (JACOBY et al., } \\
\text { 1977). }\end{array}$ & $\begin{array}{l}\text { A reutilização é uma maneira de prolongar a vida útil dos } \\
\text { produtos antes que eles sejam reciclados ou descartados } \\
\text { permanentemente. A transformação de roupas em } \\
\text { trapos é um exemplo, além da customização de peças de } \\
\text { vestuário (KOCH; DOMINA, 1997; KOCH; DOMINA, } \\
\text { 1999). A adaptação dos objetos para outras finalidades } \\
\text { também é uma manifestação encontrada do } \\
\text { comportamento de reuso, a exemplo de móveis antigos } \\
\text { de jardim que são transformados em itens decorativos } \\
\text { (GREGSON et al., 2007) ou escovas de dentes } \\
\text { reaproveitadas para limpeza doméstica (JACOBY et al., } \\
\text { 1977). Com isso, têm-se que o reuso aumenta o ciclo de } \\
\text { vida útil e posterga a entrada do produto no ciclo de } \\
\text { destinação dos resíduos sólidos urbanos (DOMINA; } \\
\text { KOCH, 1999). Evers et al. (2018), nos resultados de seu } \\
\text { estudo, sugerem que os consumidores materialistas são }\end{array}$ \\
\hline
\end{tabular}


Manoela Lawall Radtke, Ana Luiza Brock, Cristina M. Ostermann e Stefânia Ordovás de Almeida Oliveira

\begin{tabular}{|c|c|c|}
\hline & & $\begin{array}{l}\text { propensos a reutilizar, encontrando novos usos aos } \\
\text { produtos, e evitando, assim, o descarte de jogar fora. }\end{array}$ \\
\hline Reciclar & $\begin{array}{l}\text { Refere-se à utilização da matéria- } \\
\text { prima do produto para produzir } \\
\text { um novo produto (WINTERICH et } \\
\text { al., 2019). A reciclagem pode ser } \\
\text { considerada como contraponto } \\
\text { ao comportamento de jogar fora. } \\
\text { Alguns estudos consideram, } \\
\text { inclusive, que todos os } \\
\text { comportamentos que não sejam } \\
\text { "jogar no lixo" são considerados } \\
\text { como reciclagem. Isso faz com a } \\
\text { reciclagem seja empregada como } \\
\text { um comportamento de descarte } \\
\text { mais abrangente (a depender do } \\
\text { autor), inclusive englobando } \\
\text { outros. }\end{array}$ & $\begin{array}{l}\text { O emprego do termo neste sentido é notado } \\
\text { especialmente em estudos sobre a indústria têxtil e } \\
\text { relacionado a questões de sustentabilidade (DOMINA; } \\
\text { KOCH, 1999; KOCH; DOMINA, 1999; KOCH; DOMINA, } \\
\text { 1997; ARANGDAD et al., 2019). No entanto, Gregson et } \\
\text { al. (2007) pontuam que os participantes do seu estudo } \\
\text { se referiram à reciclagem para descrever a circulação e } \\
\text { redistribuição de coisas excedentes, dando indícios } \\
\text { sobre como os consumidores percebem e definem o } \\
\text { conceito. Winterich et al. (2019) evidenciam que os } \\
\text { consumidores que conseguem imaginar a transformação } \\
\text { de materiais recicláveis em outros produtos têm maior } \\
\text { motivação para reciclagem. Izagirre-Olaizola et al. (2015) } \\
\text { identificaram que o comportamento de reciclagem é } \\
\text { influenciado por motivações altruístas, pela crença que a } \\
\text { contribuição individual pode fazer a diferença para } \\
\text { melhorar o meio ambiente, pelo nível de conhecimento } \\
\text { sobre os problemas ambientais atuais e pelo gênero dos } \\
\text { respondentes, sendo mais comum em mulheres. }\end{array}$ \\
\hline (Re)vender & $\begin{array}{l}\text { O comportamento de (re)venda é } \\
\text { utilizado quando um produto que } \\
\text { já pertenceu a alguém é trocado } \\
\text { por dinheiro (LAITALA, 2014) e a } \\
\text { transação pode ser realizada por } \\
\text { diferentes canais (físicos ou } \\
\text { digitais). Em relação aos tipos de } \\
\text { produtos, são exemplos itens } \\
\text { pessoais gerais, itens pessoais } \\
\text { usados atrelados a lembranças } \\
\text { indesejadas, bens usados e } \\
\text { restaurados e bens pessoais em } \\
\text { excesso, sendo a venda realizada } \\
\text { com o objetivo de liberar espaço } \\
\text { em casa e/ou ganhar dinheiro } \\
\text { (BELK et al., 1988). }\end{array}$ & $\begin{array}{l}\text { Belk et al., (1988), ao analisarem a dinâmica de um } \\
\text { mercado de trocas e vendas de bens usados, notam, } \\
\text { inclusive, que alguns dos produtos são comprados para } \\
\text { revenda. No caso das vendas em grupos de referência, a } \\
\text { identificação do vendedor com o comprador pode contar } \\
\text { mais que o próprio retorno financeiro, pois alguém com } \\
\text { interesses afins fará uso daquele produto carregado de } \\
\text { forte apelo emocional (LASTOVICKA; FERNANDEZ, 2005). } \\
\text { Da mesma forma, Brough e Isaac (2012) identificaram } \\
\text { que consumidores com maior apego emocional ao } \\
\text { produto e com maior preocupação com a forma como os } \\
\text { produtos serão usados após a transação do descarte, } \\
\text { estão mais dispostos a fornecer descontos para } \\
\text { compradores cujas intenções de uso do produto são } \\
\text { consideradas apropriadas. }\end{array}$ \\
\hline Trocar & $\begin{array}{l}\text { O descarte pela troca possibilita } \\
\text { que o consumidor se desfaça de } \\
\text { seus bens por meio de encontros } \\
\text { com outros consumidores para a } \\
\text { troca de produtos (WEBER et al., } \\
2017 \text { ). O termo é usado quando } \\
\text { ocorre a troca de um produto por } \\
\text { outro (com valor percebido } \\
\text { equivalente), mas sem considerar } \\
\text { troca monetária. }\end{array}$ & $\begin{array}{l}\text { O comportamento de troca é observado } \\
\text { prioritariamente em estudos que possuem como objeto } \\
\text { vestuário e geralmente é executado em "festas de troca } \\
\text { de roupas" com amigos e familiares (LEE et al., 2013). Na } \\
\text { maior parte dos eventos de troca, as sobras de roupas } \\
\text { são doadas para instituições de caridade. Assim, se um } \\
\text { participante não conseguir encontrar roupas para trocar, } \\
\text { ele terá a possibilidade de descartar as roupas por meio } \\
\text { de doação (WEBER et al., 2017). }\end{array}$ \\
\hline
\end{tabular}

Fonte: elaborado pelos autores (2020).

O comportamento do consumidor em relação ao descarte de produtos está exposto a influências macro e microambientais. As influências macroambientais são relacionadas a questões econômicas e culturais (CRUZ-CÁRDENAS; ARÉVALO-CHÁVEZ, 2018; GREEN et al., 2001), e as microambientais à família (LEE et al., 2013) e ao ambiente físico em torno do consumidor (CRUZ-CÁRDENAS et al., 2017). A crise causada pela pandemia da COVID-19 alterou ambos os contextos. Assim, espera-se que tenha influenciado no comportamento de 
Efeitos da COVID-19 nos comportamentos de descarte do consumidor e cenários de negócios futuros

descarte. A seguir, serão exploradas as alterações causadas pela pandemia e pelas medidas de isolamento social no contexto e nos comportamentos de consumo.

\subsection{COVID-19 E OS EFEITOS NO COMPORTAMENTO DE CONSUMO}

A pandemia da COVID-19 trouxe mudanças no curto e no médio prazo (PANTANO et al., 2020). Muitos países optaram por medidas de isolamento ou distanciamento social, em diferentes graus de severidade e controle (SHETH; 2020). Diversas das mudanças no modo de consumo foram percebidas logo no início do período de isolamento social (KIRK; RIFKIN, 2020). À medida em que os consumidores se conscientizaram sobre o potencial da pandemia, desenvolveram reações para se defender das ameaças percebidas e, após, recuperar o controle das liberdades perdidas (KIRK; RIFKIN, 2020). Com o passar do tempo, os consumidores passaram a adotar novos comportamentos resultantes das medidas de isolamento social e prevenção do contágio. Esses comportamentos foram transformados principalmente pela imposição de hábitos de higiene mais rígidos, a proibição de aglomerações em locais públicos e fechamento temporário de comércios não essenciais (KIRK; RIFKIN, 2020). Um dos fenômenos do isolamento social foi a acentuação do uso da tecnologia para conectividade profissional e social (SHETH; 2020; KIRK; RIFKIN, 2020). Outras mudanças em hábitos de consumo foram identificadas, tais como o uso da internet para compras, atividades físicas, trabalho, educação, serviços de saúde, entre outros (DONTHU; GUSTAFSSON, 2020).

Além do grande impacto causado pela pandemia na área da saúde, a COVID-19 está causando um enorme impacto na economia. No Brasil, as previsões macroeconômicas apontam a queda do PIB em - 0,68\% a - 4,5\% em 2020 (JUNIOR; SANTA RITA, 2020). Os impactos da recessão econômica podem ser observados pela escassez de renda devido ao desemprego e famílias sem alternativas para gerar receita e meios de se manterem (KOMATSU; MENEZES-FILHO, 2020).

De acordo com os dados divulgados pelo Instituto Brasileiro de Geografia e Estatística - IBGE (2020), o Brasil perdeu 7,8 milhões de postos de trabalho atingindo uma taxa oficial de desemprego de $12,9 \%$ no trimestre encerrado em maio, totalizando 12,7 milhões de pessoas (IBGE, 2020), o que reflete na renda e no poder aquisitivo da população. Contudo, pontua-se que os impactos da COVID-19 são heterogêneos no Brasil, de modo que estudo de Bezerra et al. (2020) apontam que as populações mais pobres sofreram um impacto maior do isolamento, especialmente em relação à renda.

Esse cenário demanda ações para preservar o capital e os recursos financeiros individuais e familiares, resultando em comportamentos econômicos conservadores (DONTHU; GUSTAFSSON, 2020). Nesse sentido, entende-se que a COVID-19 levou o consumidor a mudar seus hábitos de consumo, priorizando itens essenciais e básicos e diminuindo o consumo de itens supérfluos (KIRK; RIFKIN, 2020).

A percepção dos consumidores sobre as mudanças climáticas e sustentabilidade também foi impactada pela pandemia levando as pessoas a fazerem mudanças no seu estilo de vida para reduzir os impactos no meio ambiente. Como resultado, os consumidores estão mais abertos à troca de produtos e ao consumo de produtos de segunda mão (MCKINSEY; COMPANY, 2020), o que tem efeitos no tempo de vida útil dos produtos, hábitos de descarte, e consequentemente nos hábitos de consumo. Também foi verificado crescimento do movimento faça-você-mesmo (BTG PACTUAL; DECODE, 2020; KIRK; RIFKIN, 2020). Por exemplo, as menções nas mídias sociais para pintura e reformas residenciais dobraram nas 
Manoela Lawall Radtke, Ana Luiza Brock, Cristina M. Ostermann e Stefânia Ordovás de Almeida Oliveira

duas primeiras semanas de março de 2020, gerando uma maior demanda para o varejo de artigos para o lar (KIRK; RIFKIN, 2020).

Outras mudanças importantes que podem ser pontuadas é o crescimento de $12 \%$ do volume de vendas em pequenos mercados do Brasil (MUTATO, 2020), e o aumento da distribuição espontânea da renda por parte de alguns indivíduos por meio de doações e ajudas (GOOGLE; IAT, 2020; MUTATO, 2020). Por fim, pesquisas conduzidas pela Hibou e Indico (2020) e Opinion Box (2020) indicam apoio dos consumidores à economia local: $61,5 \%$ dos consumidores entrevistados mostram-se mais propensos a comprar dos negócios de suas regiões ou cidades a fim de fortalecê-los, e $57 \%$ acreditam que a compra de produtores locais ou pequenos produtores será um comportamento mantido após a pandemia.

\section{PROCEDIMENTOS METOdOLÓGICOS}

Com o objetivo de embasar a discussão e atender aos objetivos da pesquisa, optou-se por partir de uma revisão descritiva de literatura sobre comportamentos de descarte, que permitiu sumarizar o conhecimento sobre o campo estudado e revelar padrões interpretáveis (PARÉ et al., 2015). A revisão descritiva foi realizada de forma estruturada, buscando representatividade do conjunto de artigos analisados dentro da área de investigação, e ocorreu em quatro etapas: i) delineamento da pesquisa, ii) definição da estratégia de busca e seleção; iii) realização da busca na base de dados, iv) análise de resultados e interpretação dos resultados.

A revisão teve o objetivo de descrever os comportamentos de descarte encontrados na literatura. A estratégia de busca e seleção foi definida a partir da leitura do artigo seminal de Jacoby et al. (1977) e do artigo de Cruz-Cárdenas e Arévalo-Chávez (2018), identificado com a revisão sistemática mais recentemente publicada sobre o assunto. A busca foi realizada na plataforma Scopus, selecionada por ser a maior base de dados de resumos e citações de literatura revisadas por pares. Os termos utilizados na busca foram "consumer behavior" AND "product disposal" OR "product disposition" OR disposal OR disposition. Foram considerados como campos de busca título, resumo e palavras-chave.

Os critérios de busca foram previamente definidos. Utilizou-se como filtro de pesquisa o campo de conhecimento de Negócios, Gestão e Contabilidade (tradução livre do campo Business, Management and Accounting) e artigos revisados por pares, para maior confiabilidade. Resumos expandidos publicados em eventos não foram considerados. Como resultado, foram identificados 121 documentos. O conjunto selecionado contemplou artigos publicados entre 1977, ano de publicação do artigo seminal (JACOBY et al., 1977), até dezembro de 2019. Foi realizada a leitura de cada um dos nomes e resumos dos artigos e utilizou-se como critério de inclusão: i) comportamento de descarte de produtos como tópico principal do artigo; ii) área de comportamento de consumo.

Durante a leitura dos artigos selecionados, foi realizada uma busca manual considerando as referências cruzadas. Utilizou-se a técnica de bola de neve nas listas de referências das publicações identificadas, a fim de expandir o alcance analítico da busca, que passaram pelo mesmo critério de inclusão dos demais artigos. Ao final de todas as etapas, o conjunto final chegou a 46 artigos classificados e lidos na íntegra.

A análise foi sistematizada a partir da criação de uma tabela no MS Excel. Foi realizada uma etapa exploratória considerando, primeiramente, alguns dos comportamentos iniciais levantados pela taxonomia de Jacoby et al. (1977), sendo eles: dar, guardar, jogar fora e vender. A descrição dos comportamentos de descarte foi inserida manualmente, na célula de cruzamento entre autoria do artigo e comportamento específico. Ao final, foram identificados 
Efeitos da COVID-19 nos comportamentos de descarte do consumidor e cenários de negócios futuros

onze comportamentos de descarte. Com a finalização da etapa de coleta, as inserções foram analisadas e discutidas para que se chegasse à definição mais adequada de cada comportamento. Como base para discussão, foram usadas as definições sugeridas por Laitala (2014).

A segunda etapa da pesquisa foi relacionada à busca de artigos e dados sobre comportamento do consumidor e a crise da pandemia da COVID-19. Foi realizada uma pesquisa na base Scopus no mês de agosto de 2020 com os seguintes termos de busca: "covid" OR "corona" AND "consumer" AND "behavior". Os critérios foram: publicações de 2020, na área de Negócios, Gestão e Contabilidade e a pesquisa retornou em 9 artigos, sendo eles: Laato et al. (2020); Kirk e Rifkin (2020); Sheth (2020); Donthu e Gustafsson (2020); Pantano et al. (2020); Kerigan (2020); Hirsch (2020); Zwanka e Buff (2020) e Hall et al. (2020). Adicionalmente, optou-se por buscar na internet relatórios baseado em pesquisas de empresas e institutos privados que têm monitorado mudanças e tendências no comportamento de consumo. Posteriormente, foi realizada uma relação dos comportamentos de descarte descritos na literatura com as mudanças de comportamento de descarte do consumidor encontradas nos relatórios gerenciais sobre a COVID-19. Por meio desta relação, foi possível apresentar o possível impacto da COVID-19 no comportamento, descrito e discutido a seguir.

\section{RESULTADOS E DISCUSSÃO}

A primeira etapa de revisão descritiva de literatura buscou descrever os comportamentos de descarte encontrados. Ao final foram selecionados 46 artigos, sendo que 23 deles foram publicados nos último 10 anos e em 27 diferentes revistas, sendo todas internacionais. Destacando-se as publicações do Journal of Consumer Behaviour (7 artigos) e International Journal of Consumer Studies (5 artigos). A Tabela 1 apresenta a frequência de artigos por revista.

Tabela 1 - Frequência de artigos por revista

\begin{tabular}{l|c}
\multicolumn{1}{c|}{ Revistas } & Quant. \\
\hline Journal of Consumer Behaviour & 7 \\
\hline International Journal of Consumer Studies & 5 \\
\hline Clothing and Textiles Research Journal; Journal of Business Research & 3 \\
\hline $\begin{array}{l}\text { Journal of Consumer Research; Family and Consumer Sciences Research Journal; Journal of Cleaner } \\
\text { Production; Journal of Consumer Affairs; Journal of Fashion Marketing and Management }\end{array}$ & 2 \\
\hline $\begin{array}{l}\text { Psychology \& Marketing; Marketing Theory International; Journal of Retail \& Distribution } \\
\text { Management; Journal of Consumer Psychology; Journal of Consumer Studies \& Home Economics; } \\
\text { Journal of Macromarketing; Journal of Operations Management; Journal of Retailing; The } \\
\text { International Review of Retail, Distribution and Consumer Research; Journal of Marketing } \\
\text { Environment and Behavior; Transactions of the Institute of British; Geographers; Sage Open; Young } \\
\text { consumers; Research Journal of Textile and Apparel; Geoforum; Journal of Aging Studies; The } \\
\text { International Review of Retail, Distribution and Consumer Research }\end{array}$ & 1 \\
\hline
\end{tabular}

Fonte: elaborada pelos autores (2020).

Com o objetivo de verificar as principais palavras-chaves do conjunto de estudos selecionado, gerou-se uma nuvem de palavras com o auxílio do software Wordcloud (Figura 1). Algumas das palavras inseridas na busca ocuparam posição de destaque entre as palavraschave, sendo elas: "disposal", "disposition", "consumer" e "behavior". Além disso, chama-se a atenção para a ocorrência das palavras relacionadas à indústria da moda, como: "fashion" e 
"clothing". Considerando que descartes de têxteis são associados a problemas ambientais (MCNEILL et al., 2020), compreende-se a aparição desses termos. Inclusive, a revisão conduzida por Laitala (2014) foca-se em estudos sobre comportamento de descarte com ênfase na indústria da moda que foram desenvolvidos nos últimos 30 anos, sendo ela uma das indústrias que soma mais dados empíricos em pesquisas acadêmicas.

Figura 1 - Nuvem de palavras-chaves

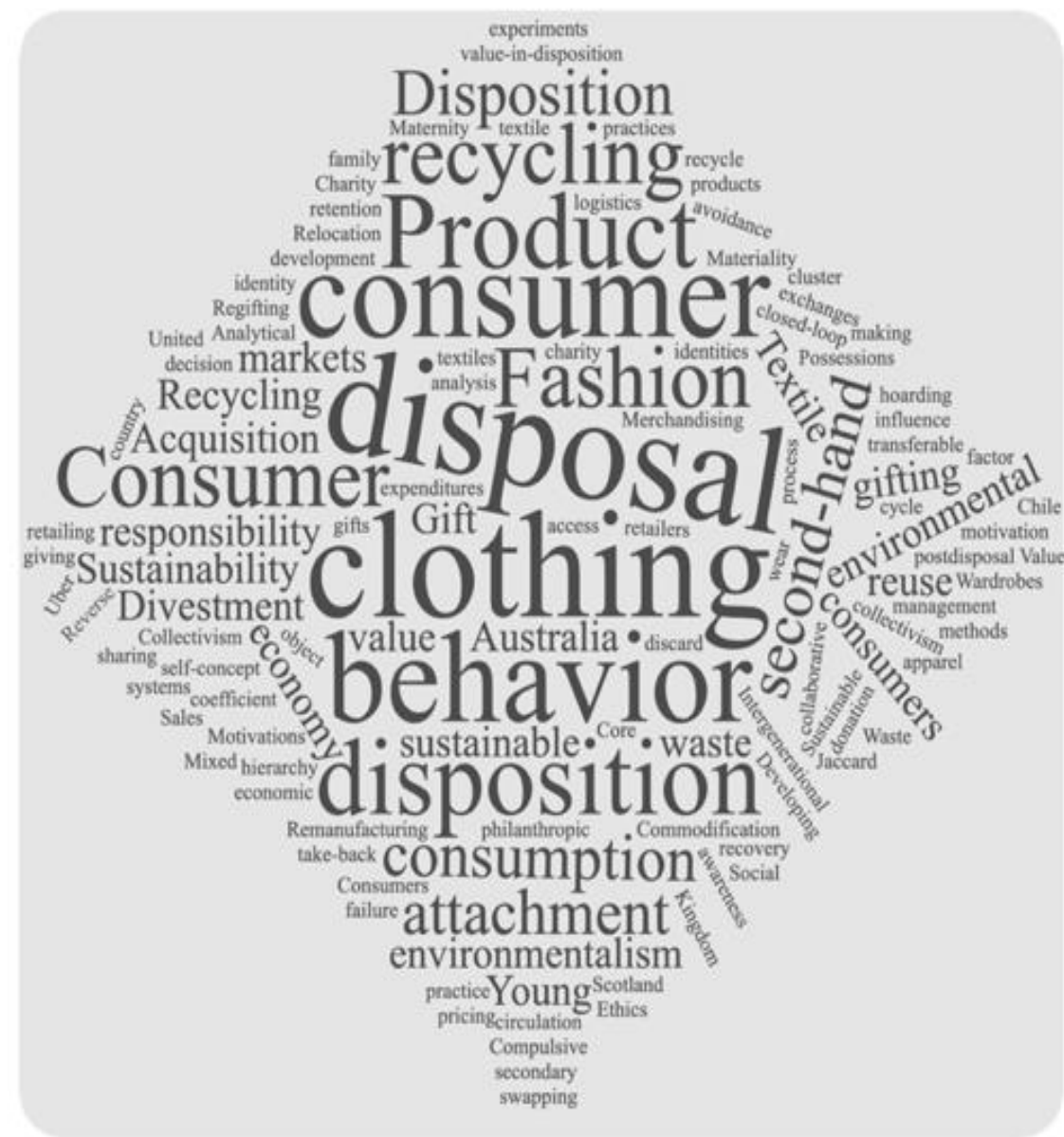

Fonte: elaborada pelos autores (2020).

Na segunda etapa da revisão, buscou-se explorar o impacto da COVID-19 nos comportamentos de descarte do consumidor à luz das pesquisas realizadas até o momento sobre mudanças e tendências no comportamento de consumo durante e pós-crise. Os resultados sugerem que os comportamentos de consumo foram afetados com a crise da COVID-19. Donthu e Gustafsson (2020) e Kirk e Rifkin (2020) descrevem três mudanças no comportamento de consumo que indicam que haverá impacto na maioria dos comportamentos de descarte: (i) aumento da preocupação ambiental; (ii) possibilidade de benefícios financeiros ao consumidor; (iii) aumento do sentimento de solidariedade.

O Quadro 2 mostra os onze tipos de comportamento de descarte apresentados no referencial teórico e os possíveis efeitos da COVID-19 nesses comportamentos. Os possíveis efeitos da COVID-19 foram sugeridos com base na leitura de relatórios gerenciais analisados. 
Efeitos da COVID-19 nos comportamentos de descarte do consumidor e cenários de negócios futuros

Quadro 2 - Impacto da COVID-19 nos comportamentos de descarte

\begin{tabular}{|c|c|c|}
\hline Tipo & Descrição do comportamento & Possível impacto da COVID-19 no comportamento \\
\hline Dar & $\begin{array}{l}\text { Entrega para pessoas próximas e } \\
\text { conhecidas, tais como amigos, } \\
\text { familiares, vizinhos, colegas de } \\
\text { trabalho ou outros conhecidos (sem } \\
\text { ganho econômico). }\end{array}$ & $\begin{array}{l}\text { Aumento da prática do comportamento por sentimento } \\
\text { de solidariedade (GOOGLE; IAT, 2020; MUTATO, 2020; } \\
\text { HIBOU; INDICO, 2020; QUALIBEST, 2020). }\end{array}$ \\
\hline Doar & $\begin{array}{l}\text { Produtos são entregues a } \\
\text { desconhecidos, em especial } \\
\text { organizações beneficentes (laicas ou } \\
\text { religiosas), sem ganho econômico } \\
\text { para o doador. }\end{array}$ & $\begin{array}{l}\text { Aumento da prática de doações a desconhecidos devido } \\
\text { ao sentimento de solidariedade (GOOGLE; IAT, 2020; } \\
\text { MUTATO, 2020; HIBOU; INDICO, 2020; QUALIBEST, } \\
\text { 2020). }\end{array}$ \\
\hline Devolver & $\begin{array}{l}\text { Produto retorna à sua origem, seja } \\
\text { pela verificação de benefício em } \\
\text { políticas ou programas de devolução } \\
\text { ou ao receber um presente que, por } \\
\text { algum motivo, precisa ser devolvido. } \\
\end{array}$ & $\begin{array}{l}\text { Aumento nas compras online resultando em um } \\
\text { aumento do comportamento de devolução de compras } \\
\text { por arrependimento e produto em desacordo com a } \\
\text { expectativa (OPINION BOX, 2020; GOOGLE; IAT, 2020; } \\
\text { MCKINSEY; COMPANY, 2020). }\end{array}$ \\
\hline Emprestar & $\begin{array}{l}\text { Quando se permite o uso de um } \\
\text { produto por outra pessoa que não o } \\
\text { proprietário durante um tempo } \\
\text { determinado, com devolução após } \\
\text { esse período. }\end{array}$ & $\begin{array}{l}\text { Aumento da prática do comportamento devido ao } \\
\text { sentimento de solidariedade (GOOGLE; IAT, 2020; } \\
\text { MUTATO, 2020; HIBOU; INDICO, 2020; QUALIBEST, } \\
\text { 2020). Por outro lado, aumento da preocupação com } \\
\text { higiene (OPINION BOX, 2020; BTG PACTUAL, 2020; } \\
\text { MUTATO, 2020; MCKINSEY; COMPANY, 2020) e o } \\
\text { distanciamento social (KIRK; RIFKIN, 2020) podem inibir } \\
\text { essa prática. }\end{array}$ \\
\hline Guardar & $\begin{array}{l}\text { Manter ou armazenar objetos que } \\
\text { ficam fora de uso. }\end{array}$ & $\begin{array}{l}\text { Aumento da prática de guardar objetos, devido a } \\
\text { restrições econômicas e financeiras da população } \\
\text { (DONTHU; GUSTAFSSON, 2020; GOOGLE; IAT, 2020; } \\
\text { MCKINSEY; COMPANY, 2020). Maior conservadorismo } \\
\text { por parte do consumidor (KIRK; RIFKIN, 2020) e } \\
\text { aumento da acumulação (SHETH, 2020). }\end{array}$ \\
\hline Jogar fora & $\begin{array}{l}\text { Descartar permanentemente como } \\
\text { parte do lixo doméstico ou por meio } \\
\text { de outras maneiras que impliquem } \\
\text { que o produto não será reutilizado } \\
\text { ou reciclado de nenhuma maneira. }\end{array}$ & $\begin{array}{l}\text { Diminuição do descarte de produtos, inclusive de } \\
\text { alimentos, devido a restrições econômicas e financeiras } \\
\text { (MUTATO, 2020; GOOGLE; IAT, 2020; MCKINSEY; } \\
\text { COMPANY, 2020). Comportamento de jogar fora pode } \\
\text { ser substituído por reciclar e reutilizar. }\end{array}$ \\
\hline (Re)presentear & $\begin{array}{l}\text { Quando algum amigo, vizinho ou } \\
\text { familiar recebe um presente que é } \\
\text { repassado com status de novo, } \\
\text { sendo que o destinatário } \\
\text { desconhece que é um represente. }\end{array}$ & $\begin{array}{l}\text { Pode-se esperar aumento no comportamento de } \\
\text { (re)presentear por questões econômicas e financeiras } \\
\text { (DONTHU; GUSTAFSSON, 2020). Por outro lado, } \\
\text { questões de higiene e de distanciamento social podem } \\
\text { inibir essa prática (MUTATO, 2020; BTG PACTUAL, 2020; } \\
\text { OPINION BOX, 2020). }\end{array}$ \\
\hline Reutilizar & $\begin{array}{l}\text { Modificar um produto para usá-lo de } \\
\text { outra forma ou com outra } \\
\text { finalidade. }\end{array}$ & $\begin{array}{l}\text { Aumento da reutilização de produtos, visando aumento } \\
\text { da vida útil e diminuição de gastos com novos produtos } \\
\text { (MCKINSEY; COMPANY, 2020; MUTATO, 2020; } \\
\text { QUALIBEST, 2020). }\end{array}$ \\
\hline Reciclar & $\begin{array}{l}\text { Utilização da matéria-prima do } \\
\text { produto para transformá-lo em } \\
\text { outro produto ou o mesmo produto } \\
\text { para outro uso, de categoria igual ou } \\
\text { inferior, tendo como resultado a } \\
\text { extensão da vida útil da matéria- } \\
\text { prima. }\end{array}$ & $\begin{array}{l}\text { Espera-se aumento no comportamento de reciclagem } \\
\text { dentro dos lares devido às restrições econômicas e } \\
\text { financeiras (DONTHU; GUSTAFSSON, 2020; GOOGLE; } \\
\text { IAT, 2020; MCKINSEY; COMPANY, 2020), tanto para } \\
\text { transformação em categoria inferior (downcycling) } \\
\text { como superior (upcycling). Por exemplo, transformar } \\
\text { fronhas e camisetas usadas em máscaras (superior) ou } \\
\text { em pano de chão (inferior) (MCKINSEY; COMPANY, } \\
2020 \text { ). }\end{array}$ \\
\hline
\end{tabular}

Fonte: elaborado pelos autores (2020). 
Observa-se que, em geral, é esperado um aumento na maioria dos comportamentos de descarte devido à crise financeira, comportamento conservador no gasto e uso de recursos e sentimento de solidariedade (DONTHU; GUSTAFSSON, 2020; KIRK; RIFKIN, 2020). Podem ser apontados como barreiras as restrições de deslocamento e movimentação, os riscos do contato social com outras pessoas e as preocupações com higiene dos produtos, que podem levar ao contágio se infectados.

Os dados levantados extrapolam o nível do consumidor. Assim, os principais efeitos observados nos modelos de negócios pós-COVID-19 como resultado das mudanças no comportamento de descarte do consumidor são descritos abaixo, discutidos e, em alguns casos, sugestões são feitas para a retomada econômica pós-crise sanitária.

Efeito 1- Digitalização da economia: As restrições de deslocamento e contato social, consequência da pandemia, levam os consumidores a buscar alternativas para manutenção das conexões sociais, com a adoção de ambientes digitais como solução (KIRK; RIFKIN, 2020). No Brasil, verificou-se a ascensão de plataformas e soluções virtuais, inclusive com uma aceleração da digitalização (MCKINSEY \& COMPANY, 2020). Esse deslocamento do ambiente físico para o digital teve como efeito a transformação de hábitos de consumo, como o uso da internet para compras, atividades físicas, educação, lazer, entre outros. Como consequência, há a consolidação de negócios que já atuavam em plataformas digitais e a migração de negócios de revenda e iniciativas de doação e compartilhamento para esse ambiente.

Efeito 2 - Movimento "faça-você-mesmo(a)": Os consumidores estão mais propensos a comprar itens de segunda mão (MCKINSEY; COMPANY, 2020) ou reformar produtos e bens já existentes (BTG PACTUAL; DECODE, 2020; KIRK; RIFKIN, 2020). A produção de conteúdo apresenta-se como forma de agregar valor aos negócios. Além da venda do produto, a comercialização de produtos para manutenção e reforma, assim como tutoriais online para a higienização, manutenção e recuperação de produtos já adquiridos podem mostrar-se relevantes para os consumidores, fortalecendo as marcas e justificando a criação de infoprodutos que podem ser comercializados, a exemplo de e-books e cursos digitais, entre outros formatos. Logo, os negócios podem agregar serviços digitais aos consumidores, aproveitando uma maior conexão digital do público.

Efeito 3 - Parcerias e apoio a soluções caseiras: Com a emergência de soluções que dialogam de forma mais próxima com as necessidades dos consumidores desencadeadas pela COVID-19, parcerias e co-criações também podem ser repensadas tendo em vista comportamentos de descarte. No caso de parcerias, destaca-se a associação entre marcas e marketplaces, nos quais as marcas podem ao mesmo tempo vender itens usados, acompanhar o sobre o ciclo de vida dos seus produtos, ter informações sobre os consumidores e fortalecer sua marca, associando-a à sustentabilidade. Na China, um crescimento de $300 \%$ em tutoriais sobre cuidados com a pele foi observado (MUTATO, 2020), e um aumento de $66 \%$ nas buscas foi verificado no Brasil entre fevereiro e abril (BTG PACTUAL; DECODE, 2020), sendo que as próprias marcas podem apoiar com conhecimento ou fechando parcerias com influenciadores que fabriquem soluções caseiras com receitas que (re)aproveitem produtos e resíduos que seriam descartados definitivamente.

Efeito 4 - Novos movimentos de consumo, novos modelos de negócios: Além da adaptação de negócios existentes, abre-se espaço também para a criação de novos modelos de negócios. Uma crescente parcela de consumidores deseja direcionar os seus recursos financeiros buscando prosperidade local (HIBOU; INDICO, 2020), motivados por um sentimento de solidariedade (DONTHU; GUSTAFSSON, 2020; KIRK; RIFKIN, 2020), sendo um campo fértil para negócios. Movimentos já existentes, mas ainda pouco usuais, também 
Efeitos da COVID-19 nos comportamentos de descarte do consumidor e cenários de negócios futuros

podem inspirar novos negócios. É o exemplo do slowconsumerism, que prega o consumo consciente, de menos quantidade de bens de maior durabilidade, ou cujo consumo cause menor impacto ambiental possível, inclusive após sua vida útil (POOKULANGARA; SHEPHARD, 2013; TODESCHINI et al., 2017).

Efeito 5 - Novos modelos de negócio a partir de resíduos: Com o isolamento social e restrições de movimentação, as atividades profissionais e educacionais foram deslocadas para os lares, deslocando também a produção de lixo e resíduos. Os consumidores ficaram mais cientes da sua produção de resíduos. Aliado à crescente preocupação com a sustentabilidade ambiental, econômica e social, nesse contexto ganham força ações e negócios que tenham como objetivo a coleta, reciclagem e reaproveitamento de resíduos domiciliares. Um exemplo de iniciativa é o projeto Crie Ação - Economia Circular Solidária ${ }^{1}$ que surgiu da ideia de criar produtos sustentáveis que podem ser feitos com materiais reutilizáveis descartados. Um dos produtos desenvolvidos durante a pandemia foi o projeto de dispensador de álcool gel feito a partir de materiais recicláveis.

Efeito 6 - Novas propostas de economia circular: A pandemia expôs fragilidades do atual sistema econômico, fortalecendo a Economia Circular como proposta de recuperação da economia alinhada à sustentabilidade (ELLEN MACARTHUR FOUNDATION, 2020). Pelo menos 50 lideranças mundiais já são signatárias da declaração conjunta para o enfrentamento dos desafios impostos pela COVID-19 a partir da Economia Circular (ELLEN MACARTHUR FOUNDATION, 2020), dando indícios de que ações neste sentido serão cada vez mais comuns. A Economia Circular dialoga com os comportamentos de descarte ao passo que observa todo o ciclo de vida dos produtos, buscando a menor geração possível de resíduos, além do prolongamento da vida de bens já em circulação. Suas bases são focadas na substituição e redução de uso de materiais na produção, recuperação de materiais (reuso por revenda, reparo, reforma, recondicionamento e manufatura) e reprocessamento (upcycling, downcycling e reciclagem) (SINGH; ORDOÑEZ, 2016). Assim, negócios de lógica circular afetam e podem ser diretamente afetados pelos comportamentos de consumo.

Por fim, percebe-se que a pandemia da COVID-19 oferece uma grande oportunidade para as empresas contribuírem para enfrentar os desafios sociais e ambientais globais urgentes (HE; HARRIS, 2020) e que novos modelos de negócios que estejam ligados ao comportamento de descarte do consumidor são pertinentes para o momento.

\section{CONSIDERAÇÕES FINAIS}

A crise da COVID-19 trouxe grandes desafios à humanidade, impactando hábitos, sentimentos, rotinas e comportamentos (KIRK; RIFKIN, 2020). Como consequência, os negócios e as cadeias de valor são afetados pela mudança no contexto social e econômico (PANTANO et al., 2020). A crise soma-se aos desafios ambientais enfrentados nos últimos anos como a mudança climática e a dificuldade de promover mudanças em processos de produção e comportamentos de consumo que preservem a biodiversidade e o meio ambiente. Neste contexto, o presente artigo buscou explorar como a crise gerada pela COVID-19 pode impactar os comportamentos de descarte, considerando esse comportamento como dimensão do consumo sustentável (WHITE et al., 2019). De forma indissociável, a crise apresenta efeitos e desafios para os negócios, com efeitos econômicos, ambientais e sociais.

\footnotetext{
${ }^{1}$ Disponível em: https://materiais.rcrambiental.com.br/projeto-crie-acao. Acesso em: 10 ago. 2020.
} 
Aprofundar o estudo dos comportamentos de descarte possui relevância gerencial na medida em que esses têm o potencial de influenciar as demais etapas do consumo. Além disso, as práticas de descarte podem impactar os modelos de negócio, gerando oportunidades para repensar e redefinir a maneira como os negócios criam, capturam e agregam valor. Por exemplo, negócios que operam sobre a lógica da Economia Circular buscam minimizar a exploração de matéria-prima orgânica e substituir o conceito de produto em "fim de vida" (HOFMANN, 2019), utilizando estratégias de negócio baseadas em reparo, manutenção, reutilização, redistribuição, reciclagem, reforma e remanufatura (HOFMANN, 2019). O comportamento de descarte impacta, assim, em oportunidades de negócio e nos modelos de negócios sustentáveis e, em especial, circulares, baseados no prolongamento da vida útil dos recursos.

A metodologia adotada possibilitou a sistematização dos comportamentos de descarte em onze tipos de comportamentos e a discussão dos efeitos da crise da COVID-19 nos comportamentos e, consequentemente, nos negócios. Em termos teóricos, a sistematização contribui para o desenvolvimento do campo teórico de comportamento do consumidor, visto que proporciona uma visão geral das práticas de decisões de descarte desses atores e possibilitou a relação dos comportamentos com um grande marco histórico vivenciado pela humanidade, que pode gerar grandes mudanças de comportamento.

As implicações práticas deste estudo são relevantes nas discussões acerca dos comportamentos e da COVID-19. Espera-se um aumento na maioria dos comportamentos de descarte, o que impacta em toda a cadeia de valor, em especial produtores, varejistas e consumidores. Surgem novas oportunidades de negócios, que demandam inovação nos atuais modelos pensados para o sistema de mercado pré-COVID-19. O potencial criativo dessas inovações, por sua vez, pode buscar a recuperação econômica de forma mais equitativa, incluindo as parcelas com menor renda e cuja desigualdade foi acentuada pela crise da COVID19. O impacto inclui múltiplos stakeholders, na esfera governamental, acadêmica e empresarial.

Enquanto limitação, destaca-se as incertezas do cenário. Vivemos um período de exceção, em que alguns comportamentos do consumidor podem ser efêmeros. Além disso, aponta-se que o artigo foi escrito em plena pandemia, de modo que os estudos e relatórios consultados compõe as fontes de dados disponíveis no momento. Espera-se que, futuramente, outros tantos estudos se somem ao conhecimento produzido sobre a pandemia da COVID-19.

Para futuros estudos, sugere-se a coleta de dados empíricos para a verificação dos comportamentos de descarte e mudanças relacionadas à COVID-19, utilizando como base a sistematização por comportamentos desenvolvida neste estudo. Tratando sobre comportamentos de descarte, sugere-se o mapeamento de comportamentos específicos menos detalhados na literatura, como trocar, devolver e (re)presentear, garantindo uma discussão mais detalhada sobre eles. Por fim, nota-se uma necessidade de mais investigações sobre os comportamentos de descarte em países em desenvolvimento (GREEN et al., 2001; BIRTWISTLE; MOORE, 2007; CRUZ-CÁRDENAS et al., 2018; CRUZ-CÁRDENAS et al., 2017). Propõe-se, especialmente, que o contexto brasileiro seja estudado, devido ao tamanho do mercado interno, ao volume de consumo e, consequentemente, ao volume de potenciais "transações de descarte". No atual cenário e entendendo que economias emergentes podem ser ainda mais impactadas pela crise sanitária, destaca-se outro fator para uma investigação mais ampla dirigida em países em desenvolvimento. 
Efeitos da COVID-19 nos comportamentos de descarte do consumidor e cenários de negócios futuros

\section{REFERÊNCIAS}

ARANGDAD, S. R.; THONEY-BARLETTA, K.; JOINES, J.; ROTHENBERG, L. Influence of demographics and motivational factors on US consumer clothing and shoes disposal behavior. Research Journal of Textile and Apparel, Hong Kong, v. 23, ed. 3, p. 170-188, 2019. DOI: 10.1108/RJTA-08-2018-0051.

ARMSTRONG, C. M.; NIINIMÄKI, K.; KUJALA, S.; KARELL, E.; LANG, C. Sustainable productservice systems for clothing: exploring consumer perceptions of consumption alternatives in Finland. Journal of Cleaner Production, Internacional, v. 97, p. 30-39, 2015. DOI: https://doi.org/10.1016/j.jclepro.2014.01.046.

BALLANTINE, P. W.; CREERY, S. The consumption and disposition behaviour of voluntary simplifiers. Journal of Consumer Behaviour: An International Research Review, Kensigton, v. 9, n. 1, p. 45-56, 2010. DOI: https://doi.org/10.1002/cb.302.

BELK, R. W.; SHERRY JR, J. F.; WALLENDORF, M. A naturalistic inquiry into buyer and seller behavior at a swap meet. Journal of Consumer Research, Oxford, v. 14, n. 4, p. 449-470, 1988. DOI: https://doi.org/10.1086/209128.

BEZERRA, A. C. V.; SILVA, C. E.; SOARES, F. R. G.; SILVA, J. A. M. Fatores associados ao comportamento da população durante o isolamento social na pandemia de COVID19. Ciência \& Saúde Coletiva, Rio de Janeiro, v. 25, s. 1, p. 2411-2421, 2020. DOI: http://dx.doi.org/10.1590/1413-81232020256.1.10792020.

BIRTWISTLE, G.; MOORE, C. M. Fashion clothing-where does it all end up? International Journal of Retail \& Distribution Management, Reino Unido, v 35, n. 3, p. 210-216, 2007. DOI: https://doi.org/10.1108/09590550710735068.

BIANCHI, C.; BIRTWISTLE, G. Sell, give away, or donate: an exploratory study of fashion clothing disposal behaviour in two countries. The International Review of Retail, Distribution and Consumer Research, Londres, v. 20, n. 3, p. 353-368, 2010. DOI: https://doi.org/10.1080/09593969.2010.491213.

BORRELLO, M.; CARACCIOLO, F.; LOMBARDI, A.; PASCUCCI, S. Consumers' perspective on circular economy strategy for reducing food waste. Sustainability, Basel, v. 9, n. 1, p. 141, 2017. DOI: https://doi.org/10.3390/su9010141.

BOYD, T. C.; MCCCNOCHA, D. M. Consumer household materials and logistics management: inventory ownership cycle. Journal of Consumer Affairs, Filadélfia, v. 30, n. 1, p. 218-218, 1996. DOI: https://doi.org/10.1111/j.1745-6606.1996.tb00732.x.

BROUGH, A. R.; ISAAC, M. S. Finding a home for products we love: How buyer usage intent affects the pricing of used goods. Journal of Marketing, Illinois, v. 76, n. 4, p. 78-91, 2012. DOI: https://doi.org/10.1509/jm.11.0181. 
BTG PACTUAL E DECODE. O legado da quarentena para o consumo. Brasil, mai., 2020. Disponível em: https://lp.decode.buzz/legado-da-quarentena-consumo. Acesso em: 10 jun. 2020.

CRUZ-CÁRDENAS, J.; GONZÁLEZ, R.; DEL VAL NÚÑEZ, M. T. Clothing disposal in a collectivist environment: A mixed methods approach. Journal of Business Research, Georgia, v. 69, n. 5, p. 1765-1768, 2016. DOI: https://doi.org/10.1016/j.jbusres.2015.10.052.

CRUZ-CÁRDENAS, J.; GONZÁLEZ, R.; GASCÓ, J. Clothing disposal system by gifting: Characteristics, processes, and interactions. Clothing and Textiles Research Journal, Las Vegas, v. 35, n. 1, p. 49-63, 2017. DOI: https://doi.org/10.1177/0887302X16675725.

CRUZ-CÁRDENAS, J.; ARÉVALO-CHÁVEZ, P. Consumer behavior in the disposal of products: Forty years of research. Journal of Promotion Management, Londres, v. 24, n. 5, p. 617-636, 2018. DOI: https://doi.org/10.1080/10496491.2018.1405514.

DOMINA, T.; KOCH, K. Consumer reuse and recycling of post-consumer textile waste. Journal of Fashion Marketing and Management: An International Journal, Reino Unido, v. 3 n. 4, p. 346-359, 1999. DOI: https://doi.org/10.1108/eb022571.

DONTHU, N.; GUSTAFSSON, A. Effects of COVID-19 on business and research. Journal of Business Research, Reino Unido, v. 117, p. 284-289, 2020. DOI: https://doi.org/10.1016/j.jbusres.2020.06.008.

ELLEN MACARTHUR FOUNDATION. Declaração conjunta Economia Circular. 15 jun. 2020. Disponível em: https://www.ellenmacarthurfoundation.org/pt/notícias/declaracaoconjunta-economia-circular. Acesso em: 03 ago. 2020.

ERTIMUR, B.; MUÑOZ, C.; HUTTON, J. G. R. A multi-perspective processual overview. Journal of Business Research, Reino Unido, v. 68, n. 9, p. 1997-2004, 2015. DOI: https://doi.org/10.1016/j.jbusres.2015.01.058.

EVERS, U.; GRUNER, R. L.; SNEDDON, J.; LEE, J. A. Exploring materialism and frugality in determining product end-use consumption behaviors. Psychology \& Marketing, Reino Unido, v. 35, n. 12, p. 948-956, 2018. DOI: https://doi.org/10.1002/mar.21147.

GAUR, J.; SUBRAMONIAM, R.; GOVINDAN, K.; HUISINGH, D. Closed-loop supply chain management: From conceptual to an action oriented framework on core acquisition. Journal of Cleaner Production, Reino Unido, v. 167, p. 1415-1424, 2017. DOI: https://doi.org/10.1016/j.jclepro.2016.12.098.

GOOGLE E IAT. Coronavírus: o mundo nunca mais será o mesmo. Brasil, Maio 2020. Disponível em: https://www.mmaglobal.com/files/328._brazil_1_5010688669204349081.pdf. Acesso em: 10 jul. 2020. 
GREEN, R. T.; MANDHACHITARA, R.; SMITH, T. Macroeconomic shock and product disposition in an emerging market. Journal of Macromarketing, California, v. 21, n. 1, p. 4760, 2001. DOI: https://doi.org/10.1177/0276146701211005.

GREGSON, N.; BEALE, V. Wardrobe matter: the sorting, displacement and circulation of women's clothing. Geoforum, Notthingham, v. 35, n. 6, p. 689-700, 2004. DOI: https://doi.org/10.1016/j.geoforum.2004.03.014.

GREGSON, N.; METCALFE, A.; CREWE, L. Moving things along: the conduits and practices of divestment in consumption. Transactions of the Institute of British Geographers, Londres, $v$. 32, n. 2, p. 187-200, 2007. DOI: https://doi.org/10.1111/j.1475-5661.2007.00253.x.

GEISSDOERFER, M.; SAVAGET, P.; BOCKEN, N.; HULTINK, E. J. The Circular Economy - A new sustainability paradigm? Journal of Cleaner Production, Reino Unido, v. 143, p. 757-768, 2017. DOI: https://doi.org/10.1016/j.jclepro.2016.12.048.

HALL, Michael C.; PRAYAG, G.; FIEGER, P.; DYASON, D. Beyond panic buying: consumption displacement and COVID-19. Journal of Service Management, v. ahead-of-print, n. ahead-ofprint. 2020. DOI: https://doi.org/10.1108/JOSM-05-2020-0151.

HANSON, J. W. A proposed paradigm for consumer product disposition processes. Journal of Consumer Affairs, Reino Unido, v. 14, n. 1, p. 49-67, 1980. DOI:

https://doi.org/10.1111/j.1745-6606.1980.tb00652.x.

HARRELL, G. D.; MCCONOCHA, D. M. Personal factors related to consumer product disposal tendencies. Journal of Consumer Affairs, Virginia, v. 26, n. 2, p. 397-417, 1992. DOI: https://doi.org/10.1111/j.1745-6606.1992.tb00034.x.

HE, H.; HARRIS, L. The Impact of Covid-19 Pandemic on Corporate Social Responsibility and Marketing Philosophy. Journal of Business Research, Internacional, v. 116, p. 176-182, 2020. DOI: https://doi.org/10.1016/j.jbusres.2020.05.030.

HIBBERT, S. A.; HORNE, S.; TAGG, S. Charity retailers in competition for merchandise: Examining how consumers dispose of used goods. Journal of Business Research, Internacional, v. 58, n. 6, p. 819-828, 2005. DOI:

https://doi.org/10.1016/j.jbusres.2003.09.011.

HIBOU E INDICO. Depois do confinamento como fica? Maio, 2020. Disponível em: http://www.lehibou.com.br/wp-content/uploads/2020/05/consumo-p\%C3\%B3sconfinamento.pdf. Acesso em: 10 jul. 2020.

HIRSCH, P. B. A breakfast of champions: brand marketing lessons from the Great Depression. Journal of Business Strategy, Nova lorque, v. 41 n. 4, p. 63-67, 2020. DOI: https://doi.org/10.1108/JBS-04-2020-0081. 
HOFMANN, F. Circular business models: Business approach as driver or obstructer of sustainability transitions? Journal of Cleaner Production, Reino Unido, v. 224, p. 361-374, 2019. DOI: https://doi.org/10.1016/j.jclepro.2019.03.115.

IBGE. Devido à pandemia, pelo menos 3 milhões de pessoas ficam sem trabalho no país. 2020. Disponível em: https://agenciadenoticias.ibge.gov.br/agencia-noticias/2012-agenciade-noticias/noticias/28613-em-quatro-meses-de-pandemia-3-milhoes-de-pessoas-ficamsem-trabalho-no-pais. Acesso em: 10 jul. 2020.

IZAGIRRE-OLAIZOLA, Julen; FERNÁNDEZ-SAINZ, Ana; VICENTE-MOLINA, M. Azucena. Internal determinants of recycling behaviour by university students: a cross-country comparative analysis. Nova Jersey. International Journal of Consumer Studies, v. 39, n. 1, p. 25-34, 2015. DOI: https://doi.org/10.1111/ijcs.12147.

JACOBY, J.; BERNING, C. K.; DIETVORST, T. F. What about disposition? Journal of Marketing, California, v. 41, n. 2, p. 22-28, 1977. DOI: https://doi.org/10.1177/002224297704100212.

JUNIOR, R. R. F.; SANTA RITA, L. P. Impactos da Covid-19 na Economia: limites, desafios e políticas. Revista Teste, Bahia, v. 1, n. 7, p. 35-47, 2020. DOI:

http://dx.doi.org/10.9771/rf.v1i7.37324.

KIRK, C. P.; RIFKIN, L. S. I'll Trade You Diamonds for Toilet Paper: Consumer Reacting, Coping and Adapting Behaviors in the COVID-19 Pandemic. Journal of Business Research, Reino Unido, v. 117. P. 124-131, 2020. DOI: https://doi.org/10.1016/j.jbusres.2020.05.028.

KOMATSU, B. K.; MENEZES-FILHO, N. Simulações de Impactos da COVID-19 e da Renda Básica Emergencial sobre o Desemprego, Renda, Pobreza e Desigualdade. São Paulo: Policy Paper, n. 43, 2020.

$\mathrm{KOCH}, \mathrm{K}$.; DOMINA, T. The effects of environmental attitude and fashion opinion leadership on textile recycling in the US. Journal of Consumer Studies \& Home Economics, Reino Unido, v. 21, n. 1, p. 1-17, 1997. DOI: https://doi.org/10.1111/j.1470-6431.1997.tb00265.x.

$\mathrm{KOCH}, \mathrm{K}$.; DOMINA, T. Consumer textile recycling as a means of solid waste reduction. Family and Consumer Sciences Research Journal, Reino Unido, v. 28, n. 1, p. 317, 1999. DOI: https://doi.org/10.1177/1077727X99281001.

KORHONEN, J.; NUUR, C.; FELDMANN, A.; BIRKIE, S. E. Circular economy as an essentially contested concept. Journal of Cleaner Production, Reino Unido, v. 175, p. 544-552, 2018. DOI: https://doi.org/10.1016/j.jclepro.2017.12.111.

KOZLOWSKI, A.; BARDECKI, M.; SEARCY, C. Environmental impacts in the fashion industry: A life-cycle and stakeholder framework. Journal of Corporate Citizenship, Reino Unido, n. 45, p. 17-36, 2012. DOI: http://www.jstor.org/stable/jcorpciti.45.17. 
Efeitos da COVID-19 nos comportamentos de descarte do consumidor e cenários de negócios futuros

KERIGAN, N. The consumer in lockdown: Consumer-merchant payments in a mobilityconstrained environment. Journal of Payments Strategy \& Systems, v. 14, n. 2, p. 113-119, 2020. ISSN 17501-86

LAITALA, K. Consumers' clothing disposal behaviour - a synthesis of research results. International Journal of Consumer Studies, New Jersey, v. 38, n. 5, p. 444-457, 2014. DOI: https://doi.org/10.1111/ijcs.12088.

LAATO, S.; ISLAM, A. K. M. N.; FAROOQ, A.; DHIR, A. Unusual purchasing behavior during the early stages of the COVID-19 pandemic: The stimulus-organism-response approach. Journal of Retailing and Consumer Services, Reino Unido, v. 57, p. 1-12, 2020. DOI: https://doi.org/10.1016/j.jretconser.2020.102224.

LASTOVICKA, J. L.; FERNANDEZ, K. V. Three paths to disposition: The movement of meaningful possessions to strangers. Journal of Consumer Research, Oxford, v. 31, n. 4, p. 813-823, 2005. DOI: https://doi.org/10.1086/426616.

LEE, J. Y.; HALTER, H.; JOHNSON, K. K. P.; JU, H. Investigating fashion disposition with young consumers. Young Consumers, Minessota, v. 14, n. 1, p. 67-78, 2013.

DOI: https://doi.org/10.1108/17473611311305494.

MCKINSEY E COMPANY. COVID-19: O novo consumidor pós-covid. 2020. Disponível em: https://www.abcem.org.br/emkt/2020/arquivos/o_novo_consumidor_po\%CC\%81s_covid_1 9.pdf. Acesso em: 10 jul. 2020.

MCNEILL, L. S.; HAMLIN, R. P.; MCQUEEN, R. H.; DEGENSTEIN, L.; WAKES, S.; GARRETT, T. C.; DUNN, L. Waste not want not: Behavioural intentions toward garment life extension practices, the role of damage, brand and cost on textile disposal. Journal of Cleaner Production, Reino Unido, v. 206, p. 1-30, 2020. DOI:

https://doi.org/10.1016/j.jclepro.2020.121026.

MUTATO. Vida pós-covid. 2020. Disponível em: http://www.muta.to/estudo-pos-covid-19. Acesso em: 10 jul. 2020.

NORUM, P. S. Towards sustainable clothing disposition: Exploring the consumer choice to use trash as a disposal option. Sustainability, Basel, v. 9, n. 7, p. 1-14, 2017. DOI: https://doi.org/10.3390/su9071187.

OPINION BOX. Impacto nos hábitos de compra e consumo: novos dados sobre o isolamento, as apostas dos consumidores em relação às tendências que vieram para ficar e dados inéditos sobre meios de pagamento, 2020. Disponível em:

http://materiais.opinionbox.com/pesquisa-coronavirus. Acesso em: 10 jul. 2020.

PANTANO, E.; SCARPI, D.; DENNIS, C.; PIZZI, G. Competing during a pandemic? Retailers' ups and downs during the COVID-19 outbreak. Journal of Business Research, Reino Unido, v. 116, p. 209-2013, 2020. DOI: https://doi.org/10.1016/j.jbusres.2020.05.036. 
PARÉ, G.; TRUDEL, M-C.; JAANA, M.; KITSIOU, S. Synthesizing information systems knowledge: A typology of literature reviews. Information \& Management, Reino Unido, v. 52, n. 2, p. 183-199, 2015. DOI: https://doi.org/10.1016/j.im.2014.08.008.

POOKULANGARA, S.; SHEPHARD, A. Slow fashion movement: Understanding consumer perceptions - An exploratory study. Journal of Retailing and Consumer Services, Reino Unido, v. 20, n. 2, p. 200-206, 2013. DOI: https://doi.org/10.1016/j.jretconser.2012.12.002.

PRICE, L. L.; ARNOULD, E. J.; CURASI, C. F. Older consumers' disposition of special possessions. Journal of Consumer Research, Arizona, v. 27, n. 2, p. 179-201, 2000. DOI: https://doi.org/10.1086/314319.

SEGO, T. Mothers' experiences related to the disposal of children's clothing and gear: keeping Mister Clatters but tossing broken Barbie. Journal of Consumer Behaviour: An International Research Review, Reino Unido, v. 9, n. 1, p. 57-68, 2010. DOI: https://doi.org/10.1002/cb.303.

SINGH, J.; ORDOÑEZ, I. Resource recovery from post-consumer waste: important lessons for the upcoming circular economy. Journal of Cleaner Production, Reino Unido, v. 134, p. 342353, 2016. DOI: https://doi.org/10.1016/j.jclepro.2015.12.020.

SHERRY, J.F.; MCGRATH, M. A.; LEVY, S. J. The disposition of the gift and many unhappy returns. Journal of Retailing, Nova Iorque, v. 68, n. 1, p. 40-65, 1992.

SHETH, J. Impact of Covid-19 on Consumer Behavior: Will the Old Habits Return or Die?. Journal of Business Research, Reino Unido, v. 117, p. 280-283, 2020. DOI: https://doi.org/10.1016/j.jbusres.2020.05.059.

SHIM, S. Environmentalism and consumers' clothing disposal patterns: an exploratory study. Clothing and Textiles Research Journal, Arizona, v. 13, n. 1, p. 38-48, 1995. DOI: https://doi.org/10.1177/0887302X9501300105.

STÅL, H. I.; JANSSON, J. Sustainable consumption and value propositions: Exploring productservice system practices among Swedish fashion firms. Sustainable Development, Lund, v. 25, n. 6, p. 546-558, 2017. DOI: https://doi.org/10.1002/sd.1677.

TING, H.; THAICHON, P.; CHUAH, F.; TAN, S. R. Consumer behaviour and disposition decisions: The why and how of smartphone disposition. Journal of Retailing and Consumer Services, Reino Unido, v. 51, p. 212-220, 2019. DOI: https://doi.org/10.1016/j.jretconser.2019.06.002.

TOLLEFSON, J. Why deforestation and extinctions make pandemics more likely. Nature, Bethesda, v. 584, p. 175-176, 2020. DOI: 10.1038/d41586-020-02341-1.

TODESCHINI, B. V.; CORTIMIGLIA, M. N.; CALLEGARO-DE-MENEZES, D.; GHEZZI, A. Innovative and sustainable business models in the fashion industry: Entrepreneurial drivers, 
opportunities, and challenges. Business Horizons, Indiana, v. 60, n. 6, p. 759-770, 2017. DOI: https://doi.org/10.1016/j.bushor.2017.07.003.

QUALIBEST. A nova realidade. 2020. Disponível em:

https://www.institutoqualibest.com/?gclid=CjwKCAjwj975BRBUEiwA4whRBzu8bl3sjAqMl3X B9WjPiktYbC3fX65Cks1V8KW0VIJoB05I-rVboxoCIfgQAvD_BwE. Acesso em: 10 jul. 2020.

WEBER, S.; LYNES, J.; YOUNG, S. B. Fashion interest as a driver for consumer textile waste management: reuse, recycle or disposal. International Journal of Consumer Studies, Nova Jersey, v. 41, n. 2, p. 207-215, 2017 DOI: https://doi.org/10.1111/ijcs.12328.

WINTERICH, K. P.; NENKOV, G. Y.; GONZALES, G. E. Knowing what it makes: How product transformation salience increases recycling. Journal of Marketing, Internacional, v. 83, n. 4, p. 21-37, 2019. DOI: https://doi.org/10.1177/0022242919842167.

WHITE, K.; HABIB, R.; HARDISTY, D. J. How to SHIFT consumer behaviors to be more sustainable: A literature review and guiding framework. Journal of Marketing, Illinois, v. 83, n. 3, p. 22-49, 2019. DOI: https://doi.org/10.1177/0022242919825649.

ZWANKA, R.I J.; BUFF, C. COVID-19 Generation: A Conceptual Framework of the Consumer Behavioral Shifts to Be Caused by the COVID-19 Pandemic. Journal of International Consumer Marketing, Estados Unidos da América, p. 1-10, 2020. DOI: 10.1080/08961530.2020.1771646. 